\title{
Genetic diversity of Toona sinensis Roem in China revealed by ISSR and SRAP markers
}

\author{
P.Y. Xing, T. Liu, Z.Q. Song and X.F. Li \\ State Key Laboratory of Crop Biology, Shandong Agricultural University, \\ Taian, Shandong, China \\ Corresponding author: X.F. Li \\ E-mail: lixf@sdau.edu.cn
}

Genet. Mol. Res. 15 (3): gmr.15038387

Received January 6, 2016

Accepted February 19, 2016

Published July 29, 2016

DOI http://dx.doi.org/10.4238/gmr.15038387

Copyright (C) 2016 The Authors. This is an open-access article distributed under the terms of the Creative Commons Attribution ShareAlike (CC BY-SA) 4.0 License.

\begin{abstract}
Toona sinensis Roem has an important value as a type of traditional vegetable and Chinese medicinal herb, and is also a valuable source of wood in China. In this study, we used the inter-simple sequence repeat (ISSR) and sequence-related amplified polymorphism (SRAP) markers to assess the level and pattern of genetic diversity in five domesticated $T$. sinensis populations in China. Our results indicated a relatively low level of genetic diversity both at species $(H s=0.1662,0.2098$, respectively) and population levels ( $H s=0.0978,0.1145$, respectively). Molecular variance analyses revealed a relatively high degree of differentiation among populations $\left(G_{\mathrm{ST}}=0.3901,0.4498\right)$, and low levels of gene flow $\left(N_{\mathrm{m}}=0.7816\right.$ and 0.6116$)$. We divided the five populations into two groups by cluster analysis: group one consists of populations collected from the south part of China (e.g., Yuxi, Yunan Province and Zuanjiang, Chongqing Municipality), and group two contains those cultivated in north part of China (e.g., Hengshui, Hebei Province, Jinan and Rizhao, Shandong Province). The correlation of genetic
\end{abstract}


relationships among populations fits well with their geographical distribution (Mantel test; $r=0.7236$ and 0.6789 , respectively). Asexual propagation, limited gene flow and geographic isolation are most likely the key factors associated with the observed genetic structure of T. sinensis grown in China. The present study indicated that both ISSR and SRAP markers were effective and reliable for assessing the degree of $T$. sinensis genetic variations.

Key words: Toona sinensis Roem; Genetic diversity; ISSR; SRAP

\section{INTRODUCTION}

Toona sinensis (A. Juss) Roem, also known as Cedrela sinensis Jussieu, has a very long cultivation history in China and many southeast Asian countries. Its edible young leaves are used as a nutritious vegetable due to its unique aromatic flavor and values in vitamins, minerals as well as antioxidants (Park et al., 1996; Edmonds and Staniforth, 1998). Importantly, almost all parts of $T$. sinensis including seed, bark, root bark, petioles, and leaves have a number of traditional Chinese medicinal values (for example: used as febrifuge, astringent, carminative, and used for enteritis and dysentery treatments) (Xien, 1996; Edmonds and Staniforth, 1998). More recently, various other biological values discovered from the $T$. sinensis leaf extracts have been reported: anti-cancer (Chang et al., 2002; Wang et al., 2010; Yang et al., 2010), antiinflammatory (Yang et al., 2006), anti-diabetes (Hsu et al., 2003), anti-neoplastic effect (Chia et al., 2010), and inhibitory effects on Leydig cell steroidogenesis (Poon et al., 2005), severe acute respiratory syndromes and coronavirus replication (Chen et al., 2008), and antitumor (Yang et al., 2013). In addition, T. sinensis trunk is a good source of hardwood (Edmonds and Staniforth, 1998).

T. sinensis is a perennial tree and after 2300 years of cultivation in China has been adapted to a variety of environments. Its wide distribution ranges from $22^{\circ}$ to $42^{\circ} \mathrm{N}$ and between $100^{\circ}$ and $125^{\circ} \mathrm{E}$ (Lu et al., 2001; Peng and Liang, 2005) in temperate and subtropical zones, but cultivation is mainly located in eastern and central China (e.g., Hebei, Shandong, Henan, Anhui, Yunnan, Guizhou; Lu et al., 2001). In addition, countries where T. sinensis has been cultivated in South East Asia include India, Nepal, Thailand, Malaysia, and Indonesia. Interestingly, as a general cultivation practice in most of these regions, $T$. sinensis has been planted in home gardens and/or around farmers' houses. These domesticated resources are important and valuable germplasm for $T$. sinensis breeding. Indeed, several elite varieties with great flavor and high nutritious quality have been identified from these $T$. sinensis domesticated resources (Xu et al., 1995).

Urban growth in China has brought not only the economic expansion, but also caused many impacts on the environment (NRC, 2001). Some environmental impacts of urbanization are associated with green space decrease (Kong and Nakagoshi, 2006; Zhou and Wang, 2011; Zhao et al., 2013; Yang et al., 2014). The loss or degradation of green space may deprive creatures of habitats, reduce biodiversity, and disrupt the structure and process of the urban ecosystem (Kim and Pauleit, 2007). Many T. sinensis cultivated in rural areas are also negatively affected due to urbanization (Liu et al. 2010), its quantity may decrease and some valuable genetic resources will vanish soon if proper action is not taken.

In Northern China, Shandong and Hebei Provinces are two main cultivation areas for

Genetics and Molecular Research 15 (3): gmr.15038387 
T. sinensis (Lu et al., 2001) and most elite cultivars were bred from domesticated resources in these areas (Xu et al., 1995). Samples from these two provinces would represent northern resources growing in temperate zone. $T$. sinensis also distributed in many provinces in Southern China, but Yunnan and Chongqing in southwest China are regarded as diversity centers and the active differentiation areas of $T$. sinensis in China (Lu et al., 2001). Those areas belong to subtropical zones. Until now, the genetic resources cultivated under different climate conditions or different geographic locations are unclear. Such information would be useful not only for breeding and production, but also for effective genetic conservation and utilization of existing domesticated populations (El-Kassaby and Ritland, 1996). Therefore, further characterization and identification of genetic diversities of the existing domesticated T. sinensis genetic resources cultivated under different climate conditions would be beneficial for $T$. sinensis breeding and quality improvement.

In previous studies of $T$. sinensis, people mainly focused on the cultivation, effective ingredients (Park et al., 1996; Xien, 1996), and pharmacology values (Wang et al., 2010; Yang et al., 2010). Little information about $T$. sinensis diversity, germplasms, and breeding is available. Using random-amplified polymorphic DNA (RAPD) and isoenzyme approaches, Wang et al. (2008) reported the low diversity of $T$. sinensis natural resources in China. Compared with RAPD, ISSR and SRAP have higher reproducibility and are more effective for genetic diversity analyses and germplasm evaluation (Shao et al., 2010; Medri et al., 2011; Niu et al., 2015; Liu et al., 2008, 2015; Souza-Sobreira et al., 2015). Using these two marker systems, we studied the genetic diversity and genetic relationships of five $T$. sinensis populations (100 individuals/sample) representing different climates and geographical locations in China. Our objectives are: 1) to reveal the genetic diversity among and within the five domesticated populations, 2) to analyze the correlation between unweighted pair-group method of averages (UPGMA) clustering results using molecular markers, 3) to provide useful information for the future conservation of the domesticated resources and breeding programs of $T$. sinensis. To our knowledge, applications of the ISSR or SRAP markers to T. sinensis genetic diversity studies have not been reported until now.

\section{MATERIAL AND METHODS}

\section{Plant materials}

Five major domesticated T. sinensis accessions from various climates in China (e.g., Hengshui, Hebei Province; Jinan and Rizhao, Shandong Province; Yuxi, Yunnan Province, and Zuanjiang, Chongqing Municipality) were collected and used in this study (Figure 1 and Table 1). Young leaves from 20-year-old or older trees $15 \mathrm{~cm}$ in diameter, all of which were distributed over $500 \mathrm{~m}$ in distance, were collected in spring for ISSR and SRAP analyses. Each pooled leaf sample consisted of 20 randomly selected individuals to represent each independent accession.

\section{DNA extraction}

Genomic DNA was extracted from young leaves of each genetic resource using a modified cetyltrimethylammonium bromide method. The DNA was quantified by comparative analysis to diluted Lambda DNA on $1 \%$ agarose gel and stored at $-20^{\circ} \mathrm{C}$ until use.

Genetics and Molecular Research 15 (3): gmr.15038387 


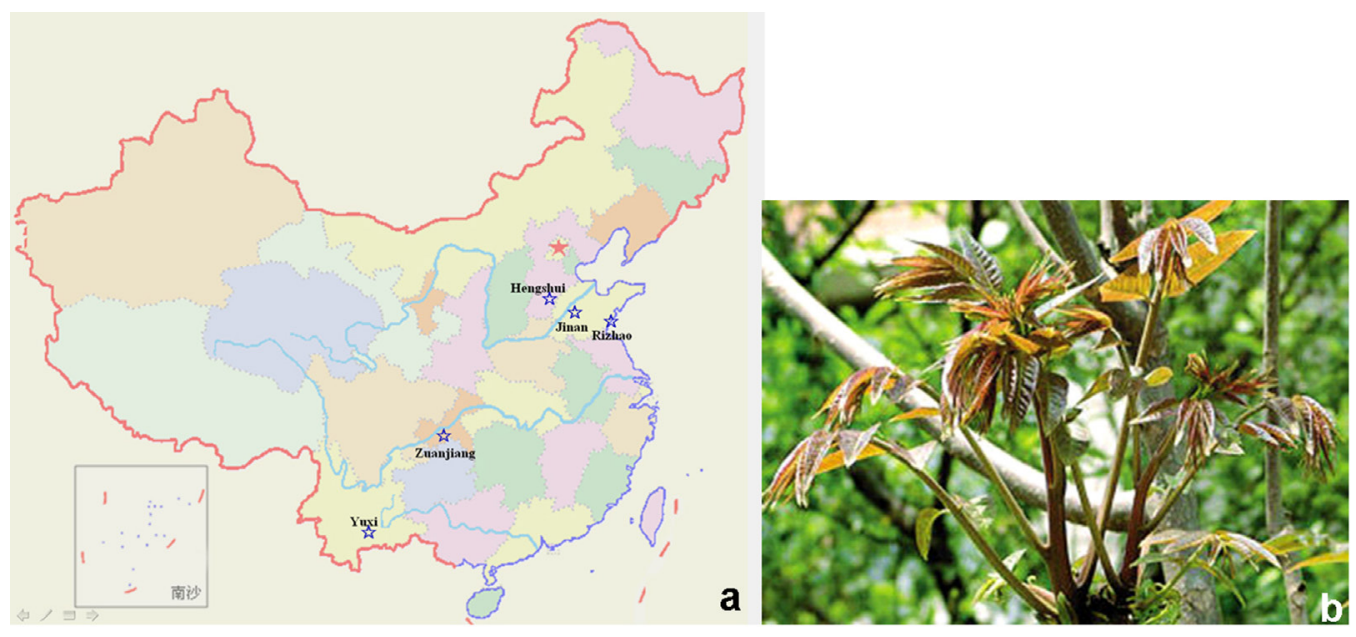

Figure 1. a. Locations of the five Toona sinensis populations cultivated in China; b. T. sinensis plant characters.

Table 1. Geographical locations of the five Toona sinensis Roem populations cultivated in China.

\begin{tabular}{l|l|c|c}
\hline Population & Location & Longitude (E) & Latitude (N) \\
\hline Hengshui & Hengshui, Hebei Province & $115^{\circ} 41^{\prime} 40^{\prime \prime}$ & $37^{\circ} 41^{\prime 2} 25^{\prime \prime}$ \\
\hline Jinan & Jinan, Shandong Province & $116^{\circ} 59^{\prime} 20^{\prime \prime}$ & $36^{\circ} 39^{\prime} 54^{\prime \prime}$ \\
\hline Rizhao & Rizhao, Shandong Province & $119^{\circ} 31^{\prime} 17^{\prime \prime}$ & $35^{\circ} 24^{\prime} 59^{\prime \prime}$ \\
\hline Yuxi & Yuxi, Yunnan Province & $102^{\circ} 32^{\prime} 43^{\prime \prime}$ & $24^{\circ} 21^{\prime} 18^{\prime \prime}$ \\
\hline Zuanjiang & Zuanjiang, Chongqing municipality & $106^{\circ} 32^{\prime} 52^{\prime \prime}$ & $29^{\circ} 33^{\prime} 57^{\prime \prime}$ \\
\hline
\end{tabular}

\section{ISSR-PCR amplification}

A total of 100 ISSR primers (Shanghai Sangon Biological Engineering Technology, Shanghai, China) were screened, and 12 of these generated clear and reproducible homologous fragments to $T$. sinensis. These 12 primers were subsequently employed for $T$. sinensis genetic diversity analyses (Table 2). PCRs were carried out in a final $20-\mu \mathrm{L}$ mixture containing $1.5 \mathrm{mM}$ $\mathrm{MgCl}_{2}, 1 \mathrm{X}$ Taq buffer, $0.4 \mathrm{mM}$ dNTP, $0.8 \mathrm{mM}$ primers, $10 \mathrm{ng}$ template DNA, and $0.5 \mathrm{U}$ Taq DNA polymerase (TaKaRa Biotechnology, Dalian, China). DNA amplification was performed under the following thermal conditions: initial denaturation at $94^{\circ} \mathrm{C}$ for 5 min followed by 45 cycles of denaturation at $94^{\circ} \mathrm{C}$ for $30 \mathrm{~s}$, annealing at $51^{\circ} \mathrm{C}$ for $45 \mathrm{~s}$, primer extension at $72^{\circ} \mathrm{C}$ for $90 \mathrm{~s}$, and a final extension at $72^{\circ} \mathrm{C}$ for $5 \mathrm{~min}$. The PCR-amplified products were separated on $6 \%$ denaturing polyacrylamide gel (acrylamide:bisacrylamide $=29: 1$ ) and then silver stained.

\section{SRAP-PCR amplification}

Combinations of nine different SRAP primers were employed using three forward primers and six reverse primers (Table 2). The final volume of each SRAP primer combination for PCR was $25 \mu \mathrm{L}$ containing $1.5 \mathrm{mM} \mathrm{MgCl}_{2}, 20 \mathrm{ng}$ genomic DNA, $0.2 \mathrm{mM}$ dNTP, $0.5 \mathrm{mM}$ 
primers, and $1 \mathrm{U}$ Taq polymerase, $1 \mathrm{X}$ Taq buffer (TaKaRa Biotechnology). DNA amplification was performed under the conditions of initial denaturation at $94^{\circ} \mathrm{C}$ for $5 \mathrm{~min}$, and 5 cycles of each of the remaining three steps: 1) denaturation at $94^{\circ} \mathrm{C}$ for $\left.1 \mathrm{~min}, 2\right)$ annealing at $35^{\circ} \mathrm{C}$ for $1 \mathrm{~min}$, and 3) elongation at $72^{\circ} \mathrm{C}$ for $2 \mathrm{~min}$. The following annealing temperature ( $30 \mathrm{cycles}$ ) was increased to $50^{\circ} \mathrm{C}$, whereas the final elongation temperature was maintained at $72^{\circ} \mathrm{C}$ for 5 min. The PCR T. sinensis products were separated on $6 \%$ denaturing polyacrylamide gel (acrylamide:bisacrylamide $=29: 1$ ) and then silver stained.

\section{Data analysis}

The amplified bands were scored as present (1) or absent (0) across all T. sinensis samples. The resulting 1/0 matrix data were analyzed using the POPGENE version 1.32 (Francis and Yang, 2000). The following genetic diversity parameters, including the percentage of polymorphic bands, Shannon's information index $(I)$ and Nei's gene diversity $(H)$ were estimated at both species and population levels.

Gene differentiation among the populations was estimated by coefficient of gene differentiation $\left(G_{\mathrm{ST}}\right)$ and gene flow $\left(N_{\mathrm{m}}\right)$ using POPGENE version 1.32 (Francis and Yang, 2000). To examine the genetic relationship among the germplasm studied, Nei's genetic distance was generated by POPGENE, and used for a dendrogram construction with the UPGMA with 1000 permutations of boot strapping using the TFPGA software, version 1.3 (Miller, 1997). The Mantel test was performed to estimate a correlation between the matrices of Nei's genetic distances and of geographical distances using NTSYS-pc version 2.1 (1000 permutations; Rohlf, 2000). Correlation between similarity matrices generated by ISSR and SRAP dataset was calculated by means of the Mantel test. To assess the distribution of genetic diversity of $T$. sinensis in five cultivation bases, the POPGENE program was used to analyze genetic differentiation from both ISSR and SRAP data.

\section{RESULTS}

\section{Polymorphism and genetic diversity of $T$. sinensis populations}

The selected 12 ISSR primers generated a total of 83 clear and reproducible DNA fragments (Table 2 and Figure 2), 46 of them $(55.42 \%)$ were polymorphic. Variation in band numbers ranged from 3 (UBC826) to 11 (UBC891), with an average of 3.83 polymorphic fragments per primer. Meanwhile, nine SRAP primer combinations amplified a total of 57 clear and scorable bands (Table 2 and Figure 3), 39 of which $(68.42 \%)$ were polymorphic. Each polymorphic SRAP primer created 2 (M2E6) to 10 bands (M10E3), averaging numbers of bands and polymorphic bands per primer being 6.33 and 4.33, respectively.

Table 3 summarizes the ISSR and SRAP data obtained from each $T$. sinensis population. The ISSR analyses at the species level resulted in $H$ of 0.1662 and $I$ of 0.2585 , indicating a low range of genetic diversity in T. sinensis. Similarly, low genetic diversity was also found at the population level: the mean of " $H$ " $=0.0978$, ranging from 0.0106 (population grown in Rizhao, Shandong, China) to 0.1416 (population grown in Yuxi, Yunnan, China). Interestingly, the SRAP analyses at the species level generated the means of " $H$ " and " $P$ " being 0.2098 and 0.3225 , respectively, whereas the same studies at the population level resulted in the averages of the same two parameters, " $H$ " $=0.1145$ (ranging from 0.0472 to 0.1728 )

Genetics and Molecular Research 15 (3): gmr.15038387 
and " $P$ " $=0.1717$ (ranging from 0.0754 to 0.2545 ) (Table 3). Compared with ISSR, SRAP analysis generated higher genetic diversities, and yet such genetic diversities detected in these domesticated genetic resources are considered low.

\begin{tabular}{|c|c|c|c|c|c|c|c|}
\hline \multicolumn{4}{|c|}{ ISSR } & \multicolumn{4}{|c|}{ SRAP } \\
\hline Primer & Bands generated & No. of polymorphic loci & Percentage of polymorphic bands (\%) & Primer & Bands generated & No. of polymorphic loci & Percentage of polymorphic bands $(\%)$ \\
\hline UBC817 & 7 & 5 & 71.43 & M2E1 & 7 & 6 & 85.71 \\
\hline UBC818 & 7 & 6 & 85.71 & M2E3 & 6 & 5 & 83.33 \\
\hline UBC823 & 7 & 3 & 42.86 & M2E5 & 4 & 3 & 75.00 \\
\hline UBC 825 & 7 & 3 & 42.86 & M2E6 & 2 & 1 & 50.00 \\
\hline UBC826 & 3 & 0 & 0.00 & M4E5 & 6 & 4 & 66.67 \\
\hline UBC838 & 7 & 2 & 28.57 & M4E4 & 6 & 4 & 66.67 \\
\hline UBC841 & 6 & 5 & 83.33 & M4E9 & 7 & 6 & 85.71 \\
\hline UBC842 & 7 & 4 & 57.14 & M10E3 & 10 & 7 & 70.00 \\
\hline UBC858 & 6 & 3 & 50.00 & M10E6 & 9 & 3 & 33.33 \\
\hline UBC859 & 6 & 3 & 50.00 & & & & \\
\hline UBC878 & 9 & 7 & 77.78 & & & & \\
\hline UBC891 & 11 & 5 & 45.45 & & & & \\
\hline Total & 83 & 46 & 55.42 & Total & 57 & 39 & 68.42 \\
\hline Average & 6.92 & 3.83 & 52.93 & Average & 6.33 & 4.33 & $\begin{array}{l}68.49 \\
\end{array}$ \\
\hline
\end{tabular}

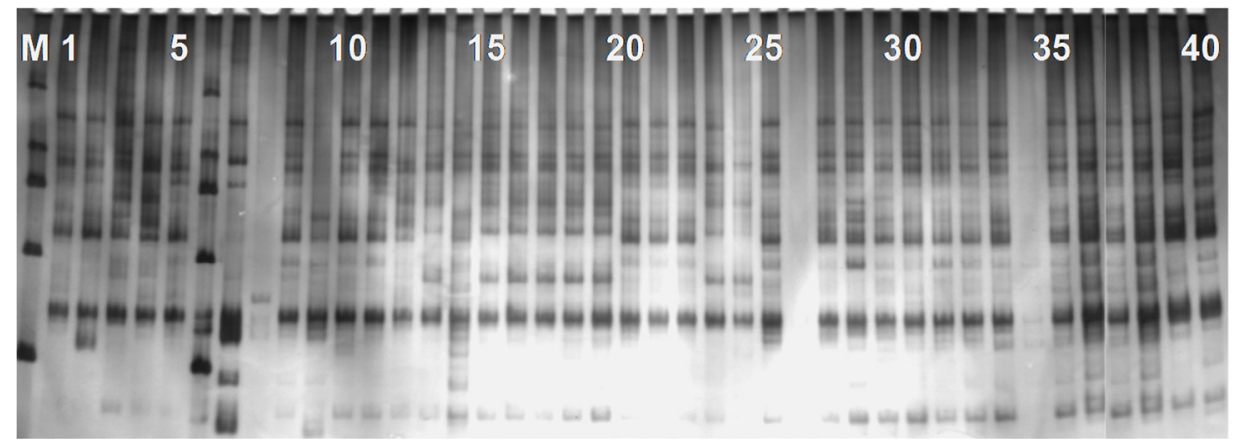

Figure 2. ISSR-amplified result of Toona sinensis by primer UBC878. Lanes 1-20= samples from Hengshui, Hebei Province; lanes 20-40= samples from Jinan, Shandong Province. Lane $M=$ DL2000 DNA marker.

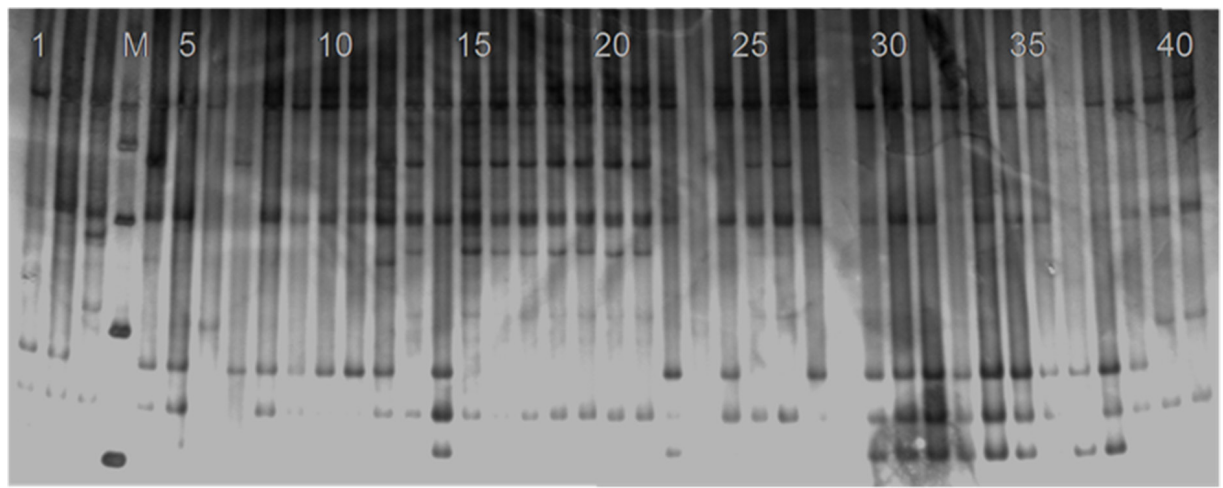

Figure 3. SRAP-amplified result of Toona sinensis by primer E10M3. Lanes 1-20= samples from Hengshui, Hebei Province; lanes 20-40= samples from Jinan, Shandong Province. Lane $M=$ DL2000 DNA marker. 
Table 3. Genetic diversity of Toona sinensis populations revealed by ISSR and SRAP.

\begin{tabular}{|c|c|c|c|c|c|c|c|c|}
\hline \multirow[t]{2}{*}{ Populations } & \multicolumn{4}{|c|}{ ISSR } & \multicolumn{4}{|c|}{ SRAP } \\
\hline & $\bar{A}$ & РPB (\%) & H & $I$ & $\bar{A}$ & РPB (\%) & $\mathrm{H}$ & $I$ \\
\hline \multicolumn{9}{|l|}{ Northern group } \\
\hline Hengshui & 30 & 36.14 & 0.1074 & 0.1652 & 15 & 26.32 & 0.0822 & 0.1251 \\
\hline Jinan & 24 & 28.92 & 0.1115 & 0.164 & 17 & 29.82 & 0.112 & 0.1662 \\
\hline Rizhao & 4 & 4.82 & 0.0106 & 0.0172 & 11 & 19.3 & 0.0472 & 0.0754 \\
\hline \multicolumn{9}{|l|}{ Southern group } \\
\hline Yuxi & 29 & 34.94 & 0.1416 & 0.2072 & 26 & 45.61 & 0.1582 & 0.2372 \\
\hline Zuanjiang & 29 & 34.94 & 0.1177 & 0.1793 & 25 & 43.86 & 0.1728 & 0.2545 \\
\hline Population average & 23.20 & 27.95 & 0.0978 & 0.1466 & 18.80 & 32.98 & 0.1145 & 0.1717 \\
\hline Species level & 46 & 55.42 & 0.1662 & 0.2585 & 39 & 68.42 & 0.2098 & 0.3225 \\
\hline
\end{tabular}

$\mathrm{A}=$ number of polymorphic loci; PPB = percentage of polymorphic bands; $\mathrm{H}=$ Nei's gene diversity; $\mathrm{I}=\mathrm{Shannon}$ 's information index.

The genetic diversity levels in the five populations studied were variable. In general, genetic resources collected from the south parts of China, for example, Yuxi population, Yuanan Province (" $H$ " $=0.1416,0.1582$ by ISSR and SRAP respectively) and Zuanjiang population, Chongqing Municipality (" $H$ " $=0.1177,0.1728$ ) showed relatively higher genetic diversity levels than those from the north parts of China, for example, Rizhao population (" $H$ " $=0.0106,0.0472$ ), Jinan population (" $H$ " $=0.1115,0.112$ ) and Hengshui population, Hebei Province (“ $H$ " $=0.1074,0.082$ ) (Table 3).

\section{Genetic differentiation among $T$. sinensis populations}

The $G_{\mathrm{ST}}=0.3901$ and 0.4498 by ISSR and SRAP, respectively, suggested that genetic differentiation of five $T$. sinensis populations in China was fairly high, indicating that about $39.01 \%$ (ISSR) or $44.98 \%$ (SRAP) of the genetic variation was among populations. Gene flow, the movement of genes within and between populations, is negatively correlated with gene differentiation (Grant, 1991), but is very important for population transfer and plant evolution, and is transferred by pollen and/or seed between populations for seed plant (Hamrick, 1987). In the current study, $N_{\mathrm{m}}$ of $T$. sinensis was 0.7816 and 0.6116 detected by ISSR and SRAP markers, and this low level of migration will lead to divergence and prevent combination between populations.

\section{Genetic identity and genetic distance among populations}

To further investigate genetic variations among the five T. sinensis populations, Nei's unbiased measures of genetic distance were evaluated (Table 4). Based on the ISSR analyses (above the diagonal), the Nei's genetic distance among populations ranged from 0.0319 to 0.1688 , with an average of 0.0816 , suggesting a low genetic distance among the five populations. However, Nei's genetic distances between Southern collections (e.g., Yuxi, Yunnan Province and Zuanjiang, Chongqing municipality) and Northern collections (e.g., Hengshui, Hebei; Jinan and Rizhao, Shandong) were generally larger than the distances within the populations cultivated in each individual region. For example, populations cultivated in Rizhao, Shandong and Yuxi, Yunnan showed the largest genetic variation (0.1688), and geographically the two locations are the furthest in distance. Conversely, the least genetic distance $(0.0319)$ was found between samples collected from Jinan, and Hengshui, and geographically these two cities are closest in distance. The SRAP analyses (below the diagonal) resulted in the same trend: the 
largest genetic difference (0.2630) was shown between populations of Rizhao and Yuxi. When the two sets of data were compared, it was found that the average genetic distance $(0.1372)$ derived from SRAP markers (below the diagonal) was higher than that $(0.0816)$ resulted from the ISSR markers. However, both ISSR and SRAP markers indicated the low genetic variations within the samples from the same region, and such variation increased between samples of south China with those of north China.

Table 4. Nei's unbiased measures of Nei's genetic distance revealed by ISSR and SRAP.

\begin{tabular}{l|c|c|c|c|c}
\hline Population & Hengshui & Jinan & Rizhao & Yuxi & Zuanjiang \\
\hline Hengshui & - & 0.0319 & 0.0509 & 0.0877 & 0.0695 \\
\hline Jinan & 0.0772 & - & 0.0974 & 0.0975 & 0.0813 \\
\hline Rizhao & 0.0664 & 0.1462 & - & 0.1688 & 0.1288 \\
\hline Yuxi & 0.1308 & 0.2116 & 0.2630 & - & 0.0478 \\
\hline Zuanjiang & 0.0931 & 0.1679 & 0.1416 & 0.074 & - \\
\hline
\end{tabular}

ISSR analysis (above diagonal) and SRAP analysis (below diagonal).

Genetic relationships of these populations were further demonstrated with a dendrogram using UPGMA algorithm based on Nei's genetic distance (Figure 4A and B). Specifically, two dendrograms (Figure 4A and B) were made based on the respected data of ISSR and SRAP, and each consisted of two main clusters comprising the five populations examined. The ISSR dendrogram (Figure 4A) showed that samples from southwest China (Yuxi, Yunnan and Zuanjiang, Chongqing municipality) were in one cluster, whereas populations from northern China (Rizhao population, Jinan population and Hengshui population) were in the other cluster. The northern cluster can be further grouped into two subclusters: populations of Hengshui and Rizhao constituted one sub-group, which appeared to be closer to each other, while that of Jinan was identified as a separate sub-group. Similarly, the SRAP dendrogram illustrated in Figure 4B showed the same result: populations from the south and north were grouped into two different clusters.
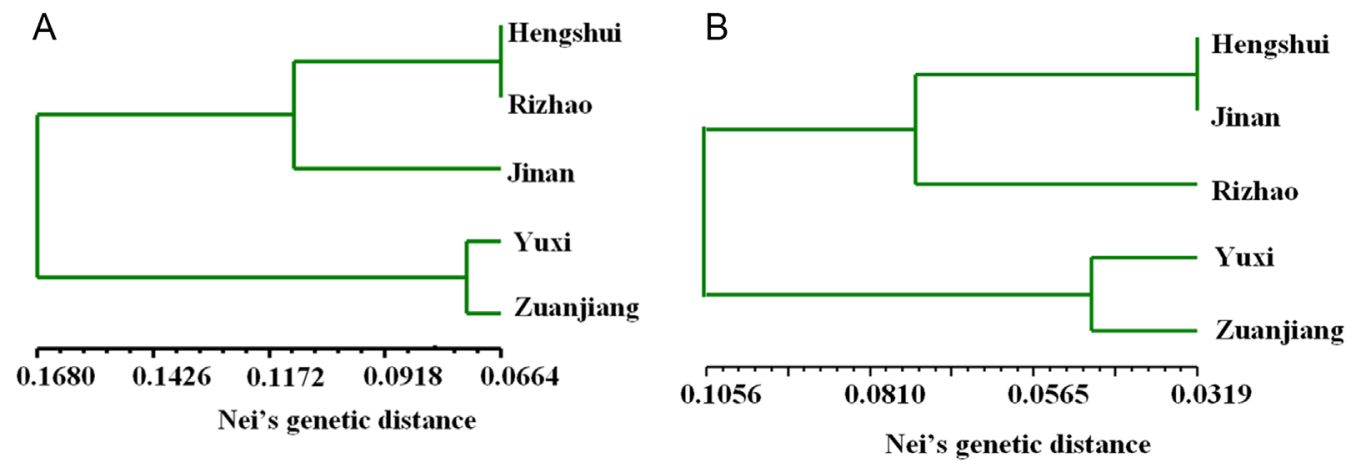

Figure 4. Dendrogram obtained by UPGMA cluster based on data from ISSR and SRAP analysis. A. ISSR. B. SRAP. 
Mantel tests indicated a very high correlation between the geographical locations and genetic distances, with $r=0.7236$ for ISSR and $r=0.6789$ for SRAP. When the similarity matrices resulting from ISSR and SRAP markers were compared, the values of " $r$ " was equal to 0.8648 , indicating a high correlation between the data generated by the two marker systems.

\section{DISCUSSION}

\section{Effectiveness of ISSR and SRAP marker for T. sinensis}

Various methods have been employed to evaluate genetic diversities in different plant species. To date, there was only one report on $T$. sinensis genetic diversity study using RAPD and isoenzymes method (Wang et al., 2008). Currently, ISSR and SRAP markers have been widely used for DNA fingerprinting, genetic diversity analyses, and germplasm evaluation due to their high efficiency and low cost (Liu et al., 2008; Shao et al., 2010). To our knowledge, this is the first report on T. sinensis genetic diversity evaluation using both ISSR and SRAP marker systems. Our results suggest that both ISSR and SRAP markers are effective and reliable. Briefly, Mantel tests showed that " $r$ " was $0.864(\mathrm{P}=0.9940)$, suggesting a high correlation between these two molecular techniques, which was in agreement with the results reported by Budak et al. (2004) and Shao et al. (2010). The results presented in this report could serve as a model for establishing an effective system for $T$. sinensis germplasm identification and genetic diversity analysis.

It is worth noting that both percentage of polymorphic bands and the mean genetic distance between genotypes (0.0816) revealed by ISSR markers were lower than those detected by SRAP markers (0.1372). These results suggest that SRAP marker system has higher resolving power than the ISSR marker system.

\section{Genetic diversity of domesticated $T$. sinensis populations in China}

The ISSR and SRAP data resulted in a similar genetic diversity pattern in the five domesticated $T$. sinensis resources ( $H s=0.1662,0.2098$, respectively). Compared with the cultivated populations of other important trees, e.g., Robinia pseudoacacia $(H s=0.2514$; Sun et al., 2009), Capparis spinosa L. (Hs = 0.2878; Liu et al., 2015), walnut (Juglans regia) (Hs $=0.2867$; Ma et al., 2011), Pitcairnia flammea (L.) John (Bromeliaceae) $(I=0.418$; SouzaSobreira et al., 2015), Yunnan tea tree [Camelliasinensis (L.) O. Kuntz] $(H s=0.413$; Liu et al., 2011), Vitis amurensis $(\mathrm{Hs}=0.5762$; $\mathrm{Wu}$ et al., 2008), the T. sinensis populations in China possess low levels of genetic diversity at the species level.

Asexual propagation of $T$. sinensis via root sucker or shoots in China has been practiced as the major production approach even though sexually propagation through seed has also been an option (Lu et al., 2001). This long history of vegetative propagation might be the cause of the low levels of genetic diversity we identified from these T. sinensis resources. In this study, we found that most samples collected from Rizhao, Shandong Province, are essentially the same with respect to their genotypes and phenotypes. These results strongly suggest that vegetative propagation is most likely a predominate production practice in this region.

\section{Genetic structure of the cultivated T. sinensis populations in China}

Based on Nei's $G_{\text {ST }}$ classifications (low: $G_{\mathrm{ST}}<0.05$, medium: $0.05^{\circ} 0.15$, and high:

Genetics and Molecular Research 15 (3): gmr.15038387 
$>0.15$; Nei, 1978), high genetic variations were observed among all $T$. sinensis populations $\left(G_{\mathrm{ST}}=0.3901,0.4498\right)$. Clearly, the $G_{\mathrm{ST}}$ values of $T$. sinensis are much higher than those $\left(G_{\mathrm{ST}}=0.25\right)$ of other perennials (Nybom and Bartish, 2000) and those $\left(G_{\mathrm{ST}}=0.27^{\circ} 0.28\right)$ of outcrossing species (Nybom and Bartish, 2000). However, the $G_{\mathrm{ST}}$ data of T. sinensis reported here are lower than those of strictly selfing species $\left(G_{\mathrm{ST}}=0.65\right)$ (Nybom and Bartish, 2000). Geographic isolation between the two populations grown in southern China and northern China may have played an important role in promoting differentiation and enlarging the genetic distance. Our T. sinensis genetic differentiation studies support the notion that species breeding systems, genetic drifts, and/or geographic isolation of populations could contribute to such a high level of population differentiation as proposed by Hogbin and Peakall (1999). Our results also suggest that sustained asexual propagation restricts gene flow $\left(N_{\mathrm{m}}=0.7816\right.$ and 0.6116$)$ and is responsible for the low genetic diversity and high genetic differentiation.

\section{Conservation implications}

Based on this study, we propose an appropriate strategy for conserving the two types of $T$. sinensis in China as they have been used as vegetable or as medicine. Since there is a low level of genetic diversity within each of these domestic $T$. sinensis population, we suggest that collection for domestic resources and conservation are immediately necessary. On the other hand, significant genetic differentiation is present between the southern group and northern group, and little gene flow appears to exist between them. These data suggest that while the conservation of genetic variability to preserve different genotypes in this species is necessary, maintaining the diversified cultivation populations is equally important. Because there is large genetic distance and ecological difference between populations grown in southern China and northern China, these two germplasm resources should be reserved independently. Additionally, the present study reveals that the diversity level of $T$. sinensis populations from southern China is much higher than that of populations from northern China. Further investigation on genetic variations present in the populations cultivated in southern China is needed.

\section{Conflicts of interest}

The authors declare no conflict of interest.

\section{ACKNOWLEDGMENTS}

Research supported by the National Natural Science Foundation of China (\#81001603) and the Natural Science Foundation of Shandong Province (\#ZR2015HM020).

\section{REFERENCES}

Budak H, Shearman RC, Parmaksiz I and Dweikat I (2004). Comparative analysis of seeded and vegetative biotype buffalograsses based on phylogenetic relationship using ISSRs, SSRs, RAPDs, and SRAPs. Theor. Appl. Genet. 109: 280-288. http://dx.doi.org/10.1007/s00122-004-1630-z

Chang HC, Hung WC, Huang MS and Hsu HK (2002). Extract from the leaves of Toona sinensis roemor exerts potent antiproliferative effect on human lung cancer cells. Am. J. Chin. Med. 30: 307-314. http://dx.doi.org/10.1142/ $\underline{\mathrm{S} 0192415 \mathrm{X} 02000223}$

Chen CJ, Michaelis M, Hsu HK, Tsai CC, et al. (2008). Toona sinensis Roem tender leaf extract inhibits SARS coronavirus

Genetics and Molecular Research 15 (3): gmr.15038387 
replication. J. Ethnopharmacol. 120: 108-111. http://dx.doi.org/10.1016/j.jep.2008.07.048

Chia YC, Rajbanshi R, Calhoun C and Chiu RH (2010). Anti-neoplastic effects of gallic acid, a major component of Toona sinensis leaf extract, on oral squamous carcinoma cells. Molecules 15: 8377-8389. http://dx.doi.org/10.3390/ molecules 15118377

Edmonds JM and Staniforth M (1998). Toona sinensis (Meliaceae). Curtis's Bot. Mag 15: 186-193. http://dx.doi. org/10.1111/1467-8748.00169

El-Kassaby YA and Ritland K (1996). Genetic variation in low elevation Douglas-fir of British Columbia and its relevance to gene conservation. Biodivers. Conserv. 5: 779-794. http://dx.doi.org/10.1007/BF00051786

Francis CY and Yang RC (2000). Popgene version 1.32. http//www.ualberta.ca/_fyeh /index.htm.

Grant V (1991). The evolutionary process: a critical study of evolutionary theory. Columbia University Press, New York.

Hamrick JL (1987). Gene flow distribution of genetic variation in plant populations. In: Differentiation patterns in higher plants (Urbanska K, ed.). Academic Press, New York, 53-57.

Hogbin PM and Peakall R (1999). Evaluation of the conservation of genetic research to the management of endangered plant Zieria prostrata. Conserv. Biol. 13: 514-522. http://dx.doi.org/10.1046/j.1523-1739.1999.98182.x

Hsu HK, Yang YC, Hwang JH and Hong SJ (2003). Effects of Toona sinensis leaf extract on lipolysis in differentiated 3T3-L1 adipocytes. Kaohsiung J. Med. Sci. 19: 385-390. http://dx.doi.org/10.1016/S1607-551X(09)70481-4

Kim KH and Pauleit S (2007). Landscape character, biodiversity and land use planning: the case of Kwangju City Region, South Korea. Land Use Policy 24: 264-274. http://dx.doi.org/10.1016/j.landusepol.2005.12.001

Kong FH and Nakagoshi N (2006). Spatial-temporal gradient analysis of urban green spaces in Jinan, China. Landsc. Urban Plan. 78: 147-164. http://dx.doi.org/10.1016/j.landurbplan.2005.07.006

Liu BY, Li YY, Sun XM, Tang YC, et al. (2011). Assessment of genetic diversity of tea germplasm from Yunnan province of China. Acta Bot. Boreal. Occident. Sin. 31(5): 0861-0867.

Liu C, Xue GP, Cheng B, Wang X, et al. (2015). Genetic diversity analysis of Capparis spinosa L. populations by using ISSR markers. Genet. Mol. Res. 14: 16476-16483. http://dx.doi.org/10.4238/2015.December.9.19

Liu J, Chen YT, Jiang JM, Hua ZH, et al. (2010). Germplasm resources of Toona Sinensis and its exploitation and utilization. Practical Forestry Technology (in Chinese). (5): 56-57.

Liu LW, Zhao LP, Gong Q, Wang MX, et al. (2008). DNA fingerprinting and genetic diversity analysis of late-bolting radish cultivars with RAPD, ISSR and SRAP markers. Sci. Hortic. (Amsterdam) 116: 240-247. http://dx.doi. org/10.1016/j.scienta.2007.12.011

Lu CX, Zhang DC and Wang DB (2001). Origin and Taxonomic Position of Chinese Toon. Bull. Bot. Res. 21: 195-199.

Ma QG, Zhang JP and Pei D (2011). Genetic analysis of Walnut cultivars in China using fluorescent amplified fragment length polymorphism. J. Am. Soc. Hortic. Sci. 136: 422-428.

Medri C, Ruas EA, Ruas CF, Medri PS, et al. (2011). Population genetic structure of the tropical tree species Aegiphila sellowiana (Lamiaceae). Genet. Mol. Res. 10: 3186-3198. http://dx.doi.org/10.4238/2011.December.20.3

Miller MP (1997). Tools for Population Genetics Analysis (TFPGA), Version 1·3, Department of Biological Sciences, Northern Arizona University, Flagstaff.

National Research Council (NRC) (2001). Grand Challenges in Environmental Sciences. National Academy Press, Washington, DC.

Nei M (1978). Estimation of average heterozygosity and genetic distance from a small number of individuals. Genetics 89: 583-590.

Niu YL, Guo WY, Bai LR and Zhao JC (2015). Genetic diversity and the conservation priority of Glycine soja populations from Northern China. Genet. Mol. Res. 14: 16608-16615. http://dx.doi.org/10.4238/2015.December.11.8

Nybom H and Bartish IV (2000). Effects of life history traits and sampling strategies on genetic diversity estimates obtained with RAPD markers in plants. Plant Ecol. Evol. Syst 3: 93-114. http://dx.doi.org/10.1078/1433-8319-00006

Park JC, Yu YB, Lee JH, Choi JS, et al. (1996). Phenolic compounds from the rachis of Cedrela sinensis. Korean J. Pharmacogn. 27: 219-223.

Peng FR and Liang YW (2005). The biological characteristics and development prospects of Toona sinensis. Forestry Sci. Tech. 19: 3-6.

Poon SL, Leu SF, Hsu HK, Liu MY, et al. (2005). Regulatory mechanism of Toona sinensis on mouse leydig cell steroidogenesis. Life Sci. 76: 1473-1487. http://dx.doi.org/10.1016/j.lfs.2004.08.026

Rohlf FJ (2000) NT.SYS-pc: Numerical Taxonomy and Multivariate Analysis System, Version 2.1., Setauket, NY: Exeter Publishing, Ltd.

Shao QS, Guo QS, Deng YM and Guo H (2010). A comparative analysis of genetic diversity in medicinal Chrysanthemum morifolium based on morphology, ISSR and SRAP markers. Biochem. Syst. Ecol. 38: 1160-1169. http://dx.doi. org/10.1016/j.bse.2010.11.002

Genetics and Molecular Research 15 (3): gmr.15038387 
Souza-Sobreira FB, Souza GB, Rosado CC, Miranda FD, et al. (2015). Genetic diversity in three natural populations of Pitcairnia flammea (1.) John (Bromeliaceae) estimated by ISSR markers. Genet. Mol. Res. 14: 15892-15901. http:// dx.doi.org/10.4238/2015.December.3.1

Sun F, Yang MS, Zhang J and Gu JT (2009). ISSR Analysis of genetic diversity of Robinia pseudoacacia populations. J. Plant Genetic Resources 10: 91-96.

Wang CL, Cao JW, Tian SR, Wang YR, et al. (2008). Germplasm resources research of Toona sinensis with RAPD and isoenzyme analysis. Biologia 63: 320-326. http://dx.doi.org/10.2478/s11756-008-0066-3

Wang CY, Lin KH, Yang CJ, Tsai JR, et al. (2010). Toona sinensis extracts induced cell cycle arrest and apoptosis in the human lung large cell carcinoma. Kaohsiung J. Med. Sci. 26: 68-75. http://dx.doi.org/10.1016/S1607$\underline{551 X(10) 70010-3}$

Wu ZL, Wang J, Shen YJ and Lu WP (2008). Analysis of genetic diversity of Vitis amurensis by using SSR markers. $J$. Fruit Sci. 25: 821-827.

Xien WC (1996). Assembly of Chinese Herbs, vol. 2. People's Medical Publishing House, Beijing, pp. 459-460.

Xu MN, Chen XL, Li DS and Li ZK (1995). Study on the nutritional elements of Chinese Toona sinensis buds in improved varieties. J. Shandong Agricultural University 26: 137-143.

Yang CJ, Huang YJ, Wang CY, Wang CS, et al. (2010). Antiproliferative and antitumorigenic activity of Toona sinensis leaf extracts in lung adenocarcinoma. J. Med. Food 13: 54-61. http://dx.doi.org/10.1089/jmf.2009.1166

Yang HL, Chang WH, Chia YC, Huang CJ, et al. (2006). Toona sinensis extracts induces apoptosis via reactive oxygen species in human premyelocytic leukemia cells. Food Chem. Toxicol. 44: 1978-1988. http://dx.doi.org/10.1016/j. fct.2006.06.027

Yang S, Zhao Q, Xiang H, Liu M, et al. (2013). Antiproliferative activity and apoptosis-inducing mechanism of constituents from Toona sinensis on human cancer cells. Cancer Cell Int. 13: 12-20. http://dx.doi.org/10.1186/1475-2867-13-12

Yang YC, Fujihara M, Li BZ, Yuan XZ, et al. (2014). Structure and diversity of remnant natural evergreen broad-leaved forests at three sites affected by urbanization in Chongqing metropolis, Southwest China. Landsc. Ecol. Eng. 10: 137-149. http://dx.doi.org/10.1007/s11355-011-0160-5

Zhao J, Chen S, Jiang B, Ren Y, et al. (2013). Temporal trend of green space coverage in China and its relationship with urbanization over the last two decades. Sci. Total Environ. 442: 455-465. http://dx.doi.org/10.1016/j. scitotenv.2012.10.014

Zhou XL and Wang YC (2011). Spatial-temporal dynamics of urban green space in response to rapid urbanization and greening policies. Landsc. Urban Plan. 100: 268-277. http://dx.doi.org/10.1016/j.landurbplan.2010.12.013

Genetics and Molecular Research 15 (3): gmr.15038387 